\title{
La Democracia Líquida: exigencia de la sustentabilidad eco-política
}

\section{The Liquid Democracy: Requirement of the Eco-Political Sustainability}

\author{
Jorge Francisco Aguirre Sala ${ }^{1}$ \\ Universidad Autónoma de Nuevo León (México)
}

Recibido: 16-06-16

Aprobado: 23-06-16

\section{Resumen}

Se pretende demostrar por qué la Democracia Líquida es exigida por la sustentabilidad necesaria a la eco-política. Las premisas de argumento son: la justicia global y la soberanía ciudadana son exigencias de la sustentabilidad eco-política y, a su vez, la Democracia Líquida es el modelo que por excelencia promueve la justicia y la soberanía. El corolario es que la Democracia Líquida es la modalidad idónea para la consolidar también al eco-desarrollo. El argumento obliga a explicar conceptos medulares: sustentabilidad, uso de recursos, sentido del consumo. Para lo cual se destacan apreciaciones axiológicas de la biosfera: desde la teología hasta la economía. A su vez, el debate sobre el consumismo se enmarca en la sustentabilidad ampliada más allá de los límites de la ecología. Todo lo anterior suma argumentos a favor de la eco-política ejercida con la Democracia Líquida como la mejor instancia para la elaboración de las políticas ambientales.

Palabras-clave: soberanía, biosfera,justicia global,justicia intergeneracional.

\footnotetext{
${ }^{1}$ (jorgeaguirresala@hotmail.com). Licenciado y Doctor en Filosofía por la Universidad Iberoamericana, de Ciudad de México. Miembro del Sistema Nacional de Investigadores (sni). Actualmente es investigador en el Instituto de Investigaciones Sociales de la Universidad Autónoma de Nuevo León. Sus líneas de investigación conjugan la democracia líquida con los aportes de Internet para la participación política. Entre sus publicaciones recientes destacan: "Los límites de la representatividad política y las alternativas de la democracia líquida" en Revista Internacional de Pensamiento Político, 10, 2015; "The model of participatory democracy powered by new media" en Archiv für Rechts- und Socialphilosophie, Stuttgart, 101, 2015; "La Democracia Líquida, Los nuevos modelos políticos en la era digital”, Universidad Oberta de Catalunya, 2016.
} 


\begin{abstract}
It is intended to demonstrate why Liquid Democracy is required for the necessary sustainability of eco-politics. The premises of argument are: global justice and citizen sovereignty are demands of eco-political sustainability and the Liquid Democracy is the model that par excellence promotes justice and sovereignty. The corollary is that the Liquid Democracy is the ideal modality to consolidate also the eco-development. The argument forces us to explain core concepts: sustainability, use of resources, meaning of consumption. Axiological appreciations of the biosphere are notorious: from theology to the economy. In turn, the debate on consumerism is framed in the broader sustainability beyond the limits of ecology. All this adds up arguments in favor of the eco-politics exercised with the Liquid Democracy as the best instance for the elaboration of the environmental policies.
\end{abstract}

Key-words: sovereignty, biosphere, global justice, intergenerational justice.

\title{
1. Introducción
}

Las acciones medioambientales de sustentabilidad deben ser democráticas o no alcanzarán la permanencia y perpetuación de la biosfera. Esto implica comprender cómo y por qué las exigencias de la sustentabilidad no sólo vinculan a la economía y la industrialización, sino también a la política y, en esa medida, a sus aspiraciones democráticas. De entre las muchas maneras de concebir las relaciones entre los humanos y la biosfera, algunas proponen que el desarrollo y el crecimiento industrial sometan sin mayores miramientos a la naturaleza, otras defienden que la naturaleza marca directrices a la economía y dicta el modo correcto para usar los recursos naturales. La cuestión es importante tanto por el consumo de recursos naturales como por la regulación de los procesos industriales que producen residuos de difícil absorción en los eco-sistemas.

El uso de la naturaleza, incluyendo en ella las consecuencias para el destino del propio hombre, exigen construir una eco-política que pueda dar directrices a favor de los componentes irrenunciables de la sustentabilidad. No se trata de una petición de principio, como si se dijera que el uso sustentable que los humanos hagan de la naturaleza requiere cumplir con las condiciones técnicas de la sustentabilidad. Sino de un círculo hermenéutico en donde el todo es mayor que la suma de las partes, pues los ecosistemas incluyen además de los seres bióticos y los procesos abióticos, las estructuras y organizaciones de sus interacciones $\mathrm{y}$, en consecuencia, las dinámicas que los humanos tienen con los demás seres y entre sí. Lo cierto es que ninguna decisión puede ignorar que el ser humano no se encuentra al margen del destino que tenga la naturaleza. 
La humanidad entonces está involucrada en el uso sustentable del medio ambiente, no sólo en la perpetuación de los recursos naturales para los procesos de producción. Por ello se requiere de una eco-política que guíe tanto al desarrollo económico como a la sustentabilidad misma de la naturaleza donde biosfera, actividad industrial y humanos se encuentren. Ahora bien, dicha eco-política debe precisarse. ¿Se trata de una política medioambiental donde el desarrollo y el deseo de satisfacer las necesidades del hombre centran la atención, o se concibe en la variante de una política ecológica donde se radicaliza la conservación de los ecosistemas, si la conservación fuera incólume, entonces impondrá límites a la acción humana además de considerar la restitución, la recuperación y el cálculo de las externalidades?

Para evitar sesgos ideológicos y prejuicios en el uso del vocabulario (pues las diferencias entre el abordaje al "medio ambiente" y los "ecosistemas" históricamente se ubican en la reyerta del antropocentrismo con el ecocentrismo), se debe adoptar una versión neutral de la doble implicación donde el humano se halla involucrado en la naturaleza y naturaleza irrumpe en la existencia del humano. Esta doble implicación se expresa en la relación que poseen hábitats, hábitos y habitantes (Rozzi et. al., 2008: 115-128). En los orígenes más arcaicos de la lengua griega, la palabra ethos no significaba ética, sino madriguera; es decir, la morada donde habita un animal. Al extender esta idea a las prácticas humanas, entonces llegó a significar también las moradas de los hombres. Dicho sustantivo evolucionó también al uso como verbo y, por ende, sustantivo y verbo se legaron al latín con los vocablos hábitat y habitar, respectivamente. Cualquier hábitat incide en las maneras en que es ocupado y transformado para habitarlo, y cuando esas maneras llegan a ser regulares entonces han generado hábitos. Dichos hábitos regulan el carácter de los seres que los ocupan (los habitantes) para habitar satisfactoriamente un hábitat. No debe perderse de vista, además, que también los hábitos inciden en los hábitats. De manera que la radical dicotomía entre ecocentrismo y antropocentrismo puede ser superada (Aguirre, 2015a).

El habitar humano en sus diversos hábitats no puede considerarse de modo acrítico. Es decir, no existe un abstracto y universal habitar humano como podría suponerse en los orígenes arcaicos. Los habitantes humanos hoy en día no pueden considerarse una población única que constituya un sólo grupo frente a la naturaleza. Existe la división de clases sociales, estilos y tradiciones de consumo que hacen emerger la dimensión política de la condición humana de cara a la vivencia y manejo de los hábitats. En consecuencia, la cuestión no puede dejar al azar las diferentes formas de organización social y política que tienen los habitantes en los hábitats. Ello impacta a las nociones de justicia, ciudadanía y soberanía. 
Resultaría contradictorio que las acciones humanas, desde el básico alimentarse para sobrevivir hasta la capacidad de organizarse políticamente, dieran como resultado la extinción de la humanidad o la enajenación de su libertad. Por lo tanto, la sustentabilidad de la biosfera y con ella la permanencia de los humanos en ella, con su libre y soberana voluntad, es también una exigencia eco-política. Para explicar lo anterior y mostrar el comportamiento más sustentable, se argumenta la siguiente tesis: la Democracia Líquida es exigida por la sustentabilidad eco-política.

Con el propósito de sostener esta tesis, se parte de la explicación de un marco conceptual y las correspondientes premisas. La premisa mayor del argumento se centra en el hecho irrecusable de que la justicia global y la soberanía ciudadana son exigidas por la sustentabilidad eco-política. La premisa menor establece que la Democracia Líquida, por excelencia, es la mejor promotora de la soberanía ciudadana y concomitantemente de la justicia global. Por ende, la Democracia Líquida es exigida por la sustentabilidad eco-política. Con ello se logra el ejercicio de la soberanía dentro de una forma de organización social y política que no sólo permite el desarrollo de la ciudadanía, sino también su perpetuación y la aspiración a la justicia global. Ésta implica a las justicias de tipo ecológico intergeneracionales y de las inter-especies. El corolario es la conservación de la biosfera, misión del eco-desarrollo.

\section{Marco Conceptual}

A reserva de ampliar la descripción de la Democracia Líquida en el lugar que le corresponde dentro de las premisas del argumento, puede ilustrarse esta concepción considerando que la democracia contemporánea se debate entre el vaivén de los modelos representativos y participativos. Si bien entre ambos modelos hay un falso dilema, no obstante la soberanía no ha encontrado total satisfacción en ellos. La Democracia Líquida supera sus límites al evaluar los tipos de representación que utilizan y los instrumentos de participación con que se ejerce la política. Básicamente posee tres versiones: de voto directo, de voto mediado en los espacios ganados por partidos desplazando a los representantes partidarios y de voto mediado por apoderados proxies ad hoc sujetos a revocatoria de mandato en cualquier momento del quehacer legislativo o ejecutivo. En las dos últimas versiones aspira a la amplia deliberación entre todo el demos y para ello se vale de la inclusión de Internet como instrumento idóneo para obtener información y propiciar la comunicación.

En lo concerniente al tema ambiental, debe concebirse que la crisis ambiental no inició con los efectos palpables de la revolución industrial en la sucesión de sus diversas etapas. También entre las civilizaciones anteriores 
a la época industrial hubo extinciones. Inclusive, algunas civilizaciones se extinguieron a pesar de haberse conservado muchas especies animales y vegetales de sus entornos, tal como la civilización vikinga o la civilización maya. Es decir, no es el hombre el que siempre queda incólume al afectar a la naturaleza.

Contemporáneamente las dificultades ambientales no proceden por utilizar de suyo recursos naturales o por generar residuos, sino por una razón técnica y otra política. La razón técnica muestra que los recursos se consumen a mayor velocidad de la cual la naturaleza puede volverlos a restituir; y la generación de desechos tiene un ritmo mayor que la capacidad de absorción del entorno. El desfase entre los ciclos biogeoquímicos y los ciclos de producción humana estriba tanto en el uso de las tecnologías industriales y la contaminación como en las decisiones de producción influenciadas por el consumo y un estilo de vida; estas son las razones políticas. En pocas palabras: el humano consume y contamina a mayor velocidad, escala, nivel y profundidad que lo que la naturaleza logra recuperarse. No obstante, esto no lo hacen los humanos en general, sino sólo aquellos que tienen la capacidad técnica y económica para hacerlo y he aquí la razón política por la cual asoma la necesidad de proceder democráticamente.

La transformación que hace el hombre sobre su entorno para sobrevivir, no sólo cambia a la naturaleza, sino a la organización humana misma. El hombre inventa y fabrica instrumentos para aprovechar su entorno. Pero al utilizar esos instrumentos y su tecnología entonces se genera la apropiación y acumulación de los mismos y, en consecuencia, la división entre quienes los poseen y no los poseen, entre quienes saben utilizarlos y quienes son neófitos. Ello provoca divisiones y marcadas diferencias de clases sociales.

La apropiación, acumulación y monopolio de quienes poseen los instrumentos técnicos para aprovechar el entorno, por una parte; y el consumo de recursos y generación de residuos de quienes se benefician de la transformación del entorno, -quizá en el mismo grupo de privilegiados-, dan pauta al problema común y no privativo de la alteración del hábitat. De lo cual se ha dado testimonio por parte desde las ciencias sociales (Beck, 1998) hasta la iglesia católica (Francisco, 2015). Ante ello, las propuestas de solución (amén de las soluciones técnicas) están respectivamente divididas por los diversos intereses de grupo o clases sociales, aunque existan instancias con pretensiones de universalidad unitaria e igualitaria como los convocadas y conformadas por la Organización de Naciones Unidas (Gudynas, 2015).

A pesar de la existencia de muchas tipologías para categorizar a los diferentes intereses y grupos y sus respectivas alternativas de solución, puede adoptarse una clasificación a gran escala entre ambientalistas y ecologistas. Cada una de ellas, a su vez, con muchas variantes. La ideología de los ambientalistas 
reconoce valor a la naturaleza en función de la utilidad o servicio que presta al humano. Los ecologistas, por su parte, consideran que la naturaleza posee valor intrínseco, es decir, que es valiosa por sí misma con independencia de cualquier utilidad o jerarquización.

En este contexto, a su vez el ambientalismo posee muchas variantes. Desde el radical hasta el débil, pasando por la variedad moderada, antropocéntrica, anarquista, marxista y un larguísimo etcétera. También tiene un sinnúmero de superposiciones o intersecciones, algunas son definitivas y otras son temporales. Lo anterior ha dado pauta a la ecología social, a la economía ecológica, a la medioambiental y otro larguísimo etcétera.

Ante la variedad de intereses, perspectivas y grupos, cabe guiarse por algunas evidencias: las crisis ambientales no tienen homogénea gravedad en toda la población, aunque la alteración del hábitat sea común y no privativo. Existen efectos generalizados sobre la naturaleza como el cambio climático o el calentamiento global, pero las consecuencias correspondientes para la sobrevivencia, la salud, el grado de bienestar y las posibilidades de desarrollo están diferenciadas en las clases sociales y en el desarrollo de los distintos países. La sustentabilidad exige la tecnología adecuada para el uso de los recursos naturales, su restitución y el manejo de los residuos. Pero ello debe subordinarse a la organización soberana y democrática de la totalidad de los humanos y no sólo a los intereses de la clase dominante. En este contexto se justifica la necesidad de la democracia, en particular de la Democracia Líquida como exigencia de la sustentabilidad eco-política.

\section{Premisa mayor: la justicia global y la soberanía ciudadana son exigencias de la sustentabilidad eco-política}

Para argumentar la primera premisa es necesario explicar qué es la sustentabilidad y en particular la sustentabilidad eco-política. Ello dará pauta para requerir ambos conceptos dentro de la comprehensión de los sujetos de la premisa: justicia global y soberanía ciudadana.

Amén del enorme debate sobre los matices entre sustentabilidad y sostenibilidad, las nociones del derecho a la soberanía y su consecuente justicia global, presentan rasgos esenciales exigidos por la sustentabilidad. Es decir, si el ejercicio de la soberanía acarreara la pérdida de la misma o una auto-injusticia, entonces se habría ejercido erróneamente o como una falsa autodeterminación. Dicho desde el sentido común: el ciudadano no es soberano para convertirse en esclavo o para cometer injusticias contra sí mismo que provoquen su extinción.

Con lo anterior parecería que la noción de sustentabilidad se ha trasladado arbitrariamente de la consideración ecológica o medioambiental al campo de 
la política para evitar la extinción de la soberanía ciudadana y la democracia. En efecto, hay quienes piensan que la sustentabilidad es "exclusivamente una cuestión ecológica o física" (Foladori y Pierri 2005:205) y que en ella no debe incluirse la perspectiva social. Sin embargo, la sustentabilidad, aún de orden biológico, está vinculada con lo social y lo político. Al atacar los problemas derivados de las malas políticas públicas que provocan la inequitativa distribución de las tecnologías limpias y los recursos naturales, la irrestricta depredación en territorios de naciones vulnerables y la emisión de contaminantes de impacto global, la sustentabilidad deja de ser un problema de pretendida neutralidad científica y se convierte en un asunto eminentemente político.

El concepto más extendido de sustentabilidad se encuentra en muchos documentos mundialmente aceptados. El más conocido es El informe Brundtland o Nuestro Futuro Común. En ese informe la noción de sustentabilidad se concibe, ligada al desarrollo, como "el conjunto de aquellas acciones que satisfacen las necesidades del presente sin comprometer la capacidad de las generaciones futuras para satisfacer sus propias necesidades" (United Nations 1987: 15). Sin duda alguna, al considerar la noción de necesidades presentes, se da por supuesto que todas las clases sociales y los diversos países en escalas distintas de desarrollo pertenecen a un mismo grupo del presente y no hay diferencias. El concepto de sustentabilidad, ya puede sospecharse, también tiene matices que obedecen a intereses y al status quo político y económico.

Un evento histórico que apuntala la ampliación del concepto sustentabilidad a la esfera política se encuentra en el Plan de Aplicación de Johannesburgo de las Decisiones de la Cumbre Mundial sobre el Desarrollo Sostenible de Río de Janeiro (conocido como Agenda 21, emitida en 1992), el cual sostiene que: "La buena gestión de los asuntos públicos en los países y en el plano internacional es esencial para el desarrollo sostenible" (United Nations 1992: 8). Y para lograr dicho desarrollo sostenible en base a la buena gestión de los asuntos públicos, se enumeran, entre otras condiciones: “... las instituciones democráticas que tengan en cuenta las necesidades de la población..." (United Nations 1992: 8 [la modalidad de cursivas no se encuentra en el texto original]), así como "el respeto de los derechos humanos y las libertades fundamentales" (United Nations 1992: 9). Como puede comprenderse, la sustentabilidad exige que las decisiones adoptadas para el desarrollo contemplen, de entre las necesidades ciudadanas presentes y futuras, las decisiones de orden democrático.

De lo anterior se sigue que la sustentabilidad no se reduce a la economía medioambiental, como bien ha hecho ver Rubio (2016), y por ello no se limita al cuidado administrativo del medio ambiente, sino que se avoca a atender a la biosfera. Como ya se ha indicado en otros textos (Monjeau 2015), para efectos de una narrativa más adecuada e incluyente, en vez de vocablos como 
ambiente o medioambiente, tierra o naturaleza -inclusive creación-, entorno o mundo, ecosistema o comunidad biótica, es preferible considerar al conjunto de seres vivos humanos y no humanos, y también a los seres no vivos (debido a los procesos abióticos que impactan positiva o negativamente las cadenas alimenticias de los bióticos) y las relaciones entre todos ellos, bajo la noción de "biosfera". La denominación "biosfera" permite acentuar la preocupación axiológica y política hacia el humano, animales, plantas, suelos, aguas y comunidad biótica. La biosfera entonces comprende a los individuos, las comunidades y a las relaciones bióticas mismas. En este sentido, la Organización de Naciones Unidas, en la Declaración Universal sobre Bioética y Derechos Humanos del 19 de octubre de 2005 aboga por la protección a la biosfera. El artículo 17 de dicha declaración reza:

"Debida atención debe ser dada a la interrelación de seres humanos con otras formas de vida, a la importancia del acceso y la utilización adecuada de recursos biológicos y genéticos, al respeto por el conocimiento tradicional y al papel de los seres humanos en la protección del medio ambiente, la biosfera y la biodiversidad"

Es preferible entonces el vocablo biosfera, por encima de cualquier otro (Aguirre 2015a), porque esta noción afianza la idea de sustentabilidad en sí misma por encima de la condición económica que la condiciona al desarrollo de índole industrial. La biosfera incluye la suma de todos los ecosistemas y consecuentemente contiene la relación con el medio ambiente, incluidos los procesos bióticos y sus vínculos con lo abiótico. Como afirma críticamente el ecólogo Shahid Naeem (2013) la sustentabilidad es más que la perpetua disponibilidad de insumos para la economía de mercado. La sustentabilidad y la supervivencia de seres vivos innegablemente son necesarios en un sentido pragmático, pero no son suficientes para dotar de sentido a la vida y las relaciones entre los vivientes. Aún para ser susceptible de aprovechamiento en cuanto recurso, la biosfera requiere aportar al hombre algo más que los insumos biológicos para el simple bienestar físico o la ausencia de enfermedades. El hombre necesita dotarle de la orientación axiológica.

Ahora bien, la perspectiva axiológica no carece de jerarquías. En una primera versión se encuentra, como se ha dicho, la preferencia a considerar a la biosfera como insumos o recursos naturales para el desarrollo industrial. Esta es la interpretación reificante. Dicha interpretación se halla desde el libro del Génesis con su “...henchid la tierra y someterla” $(1,28)$. Siglos después se acendró en las ideas fundacionales del liberalismo económico expuestas por Stuart Mill en su influyente texto Principios de Economía Política publicado en 1848, en el cual consideró a la "tierra" como "suelo" (1978: 172), es decir, como elemento de explotación para la producción y acumulación del capital. 
Contemporáneamente la interpretación reificante también se encuentra en el reconocimiento que hace el Banco Mundial de la degradación ambiental por la "sobreexplotación de los recursos" (2000).

Un segundo nivel axiológico considera a la biosfera como mundo o naturaleza. Este nivel axiológico también ha tenido presencia a lo largo de la historia, aunque no tan mayoritariamente como la versión anterior. Desde la antigüedad se encuentra mezclado o emparentado con concepciones panteísticas, así por ejemplo en varios de los presocráticos, los estoicos y los neoplatónicos. Durante la edad media estuvo presente en las cosmovisiones de Juan Escoto Erígena, los Herejes del Espíritu Libre y Nicolás de Cusa. Durante el renacimiento se manifestó con los Entusiastas de la Naturaleza y Giordano Bruno. En la modernidad tuvo expresiones racionalistas e idealistas en pensadores como Spinoza, Leibniz, Herder y Hegel. En la época contemporánea, claramente diferenciado de cualquier sospecha panteísta, puede hallarse en las consideraciones de McIntyre.

Un tercer nivel axiológico, más reciente, extiende sus aristas hasta la postulación de derechos para las formas de vida no humanas. Las aportaciones de Peter Singer y Tom Regan resultaron pioneras en atribuir derechos a los animales y también las aportaciones de Christopher D. Stone y Michel Marder para atribuírselos a los vegetales. Paul Taylor, por su parte, fue uno de los primeros en reconocer el valor de los vegetales aunque no les otorga derechos.

Otro nivel axiológico percibe la biosfera como algo sobrenatural. El líder de la iglesia católica en 2009, Benedicto XVI, en su Carta Encíclica Caritas in Veritate, considera que ver a la naturaleza meramente como "mundo" es una distorsión que conlleva el peligro de reducirla sólo a recursos para la explotación. De igual modo que visualizar al mundo como mera "naturaleza" sería considerarla como fruto del azar o del determinismo evolutivo. Propone entonces que los creyentes reconozcan a la naturaleza como "la creación misma" (Párr. 48) para orientar su conducta según el mandato del Génesis -que resulta contradictorio con la expresión anteriormente aquí citada-, que impone el deber de "guardarla y cultivarla" $(2,15)$. Las estipulaciones del pontífice católico concluyen en concomitancia con el concepto de sustentabilidad: "Por tanto, los proyectos para un desarrollo humano integral no pueden ignorar a las generaciones sucesivas, sino que han de caracterizarse por la solidaridad y la justicia intergeneracional, teniendo en cuenta múltiples aspectos, como el ecológico, el jurídico, el económico, el político y el cultural" (Párr. 48). Por esta conclusión el documento de Benedicto XVI puede considerarse, junto con el de su sucesor Francisco, la Carta Encíclica Laudato si'el cuidado de nuestra casa común (2015), una apología teológica de la sustentabilidad eco-política. De ello puede dar prueba el capítulo quinto de la Laudato si' que propone el diálogo con la política internacional y las nuevas políticas nacionales y 
locales de todo el orbe en el marco de los procesos deliberativos. Tal y como corresponde al modelo de la Democracia Líquida.

Cualesquiera que sean las preferencias axiológicas resulta necesario desembocarlas en la sustentabilidad eco-política, aunque no siempre por las mismas razones. El suelo, para perpetuar los insumos de producción; la tierra, para conservar los recursos del consumo; el mundo, para restituir los servicios ecosistémicos; la naturaleza, para contar con el hábitat donde habitar; la creación, para poseer el punto de inicio y término del destino común; y dicho de manera científica, la biosfera, para que todas esas acciones se lleven a cabo en equidad no sólo inter-generacional o inter-especies, sino también dentro de la justicia global.

En lo concerniente al humano, la sustentabilidad eco-política cabe ser definida como la organización social y política por medio de la cual, de manera democrática, se establecen las políticas públicas que efectivamente logran satisfacer las necesidades ciudadanas presentes sin distinción de clase y la perpetuación de las condiciones políticas para que las generaciones futuras también satisfagan sus propias necesidades según su deseo de organización y decisiones. Al mismo tiempo, la sustentabilidad eco-política está muy atenta a evaluar las necesidades presentes y futuras desde la crítica a las necesidades creadas o falsas de un consumismo ausente de cualquier sentido axiológico. Al discernir y discriminar las necesidades falsas de aquellas que son verdaderas, entonces se garantiza la condición de soberanía frente a las ideologías del consumo depredador o del consumismo que atenta contra la justicia global.

Antes de continuar se debe hacer hincapié en algunas propuestas axiológicas contra el consumo. Así por ejemplo, debe contemplarse la autocontención como un valor orientado a la autolimitación (Linz et. al 2007). No puede desconocerse que en algunas sociedades contemporáneas europeas, no obstante, existe una preferencia al estilo de vida opuesto, es decir, al consumo irrestricto, so pretexto de saldar una deuda histórica con aquellas generaciones que padecieron muchas privaciones durante las postguerras mundiales del siglo XX. Sin duda alguna es lamentable la existencia de tal deuda histórica, como las que padecen otras tantas civilizaciones o culturas que también se encontraron en períodos de privaciones y padecimientos. Sin embargo, el concepto de sustentabilidad, amén de mirar más hacia el futuro que hacia el pasado, cuando mira de cara a los anteriores acreedores, también tiene capacidad para exigirles a sus actuales cobradores que no generen una deuda histórica anticipada para con las generaciones futuras.

La popularidad de El informe Brundtland (1987) para asir la idea de sustentabilidad, frenar el consumo y la contaminación, padece de miopía. Se enfatiza más la responsabilidad de no comprometer los recursos naturales en razón de las generaciones futuras, en vez de centrar la atención en las 
poblaciones presentes que no alcanzan a satisfacer las necesidades básicas. El asunto implica el consumo obviamente, pero de manera capital implica la distribución, redistribución y equidad de los recursos entre todos los grupos humanos que se encuentran ahora frente a la naturaleza sin desplazar su atención a los grupos futuros. Para corregir esta miopía se propone aquí la Democracia Líquida bajo las estipulaciones del eco-desarrollo.

La objeción a la autocontención no se deja esperar cuando se alega que, en todo caso, se trata de consumir sin límite bajo la fórmula de una mayor ecoeficiencia en la producción. Pero no se trata de consumir más con menos, sino de hacerlo mejor con menos. En este sentido Sempere (2009) ha ilustrado que además de la fórmula de producir y consumir mejor con menos, en términos de producción, se trata de distinguir lo necesario de lo superfluo de manera que los deseos de consumo obedezcan a verdaderos satisfactores. Mark Sagoff enfatiza que "una vida simple puede ser más valiosa que una ampulosa, y que el crecimiento económico podría ser moralmente indeseable, aun cuando fuera ecológicamente sustentable" (1995: 619). Es decir, que una vida ostentosa y opulenta, dadas las condiciones de pobreza de un amplio sector de la población mundial, no es justificable aunque resultase sustentable. De manera que no sólo se trata de consumir mejor con menos, sino de que todos puedan consumir. Pues todos, aun con menor o sin mérito alguno para consumir, están afectados por los procesos de extracción y contaminación.

En abono de lo anterior cabe insistir que la autocontención, como moderación al consumo, no se limita a una decisión personal. Bien ha denunciado U. Beck (1998); los riesgos no son impersonales aunque las responsabilidades así lo parezcan. La autolimitación en el consumo, y por ende en la producción depredadora, requiere de un compromiso común y comunitario. Ello justifica los valores y preferencias establecidos por la eco-política. En estricto sentido no existe consumo personal, porque la cadena de consumo y producción corresponde a toda la polis global. La sustentabilidad eco-política atiende, por ende, los problemas de la "glocalización" (R. Robertson 2003), entendida ésta como la conjunción de lo global con lo local donde ningún problema puede aislarse de entre las diversas esferas que, sólo aparentemente, son heterogéneas. De ahí la reconocida tesis: "piensa global y actúa local” (Dubos 1972).

\section{Premisa menor: la Democracia Líquida es promotora de la justicia global y la soberanía ciudadana}

Así como es imposible sustraerse de la biosfera, es imposible sustraerse de la glocalización o de la polis global que, a su vez, demanda las exigencias de la eco-política. Ahora bien, no puede ignorarse que la sustentabilidad eco- 
política exige el derecho a la soberanía ciudadana; no sólo para tomar las mejores decisiones en las políticas públicas referentes a los riesgos sociales no individualizables, sino para ejercer la soberanía personal por encima de la enajenación consumista, del riesgo comunitario y de la depredación anónima de la biosfera. Si bien es cierto que el concepto de soberanía se refiere al uso del poder de mando (Matteucci 1982: 1534) o del control político (Robertson 1993: 440) por parte de los gobernantes o las instancias orgánicas de gobierno hacia los ciudadanos, dicha autoridad requiere de legitimidad en oposición al uso arbitrario del poder. Implica entonces la transformación de la fuerza de cada individuo en el poder legítimo del gobierno. El paso del poder de hecho al poder de derecho (Matteucci, 1982: 1535), en otras palabras: el tránsito del derecho a la libre autodeterminación hacia el derecho de organizarse social y políticamente para enfrentar riesgos personales, comunitarios e intergeneracionales ante la depredación de la biosfera.

Las diversas perspectivas sobre la soberanía provocan la discusión sobre el depositario original de la misma o del origen de su poder. Si se inicia por el rastreo de la soberanía en la modernidad, se encontrará que Rousseau en 1762, más tardíamente que Bodin (1576) y que Hobbes (1651), en El Contrato Social alegó que el depositario original de la soberanía es el ciudadano, pues éste deposita el poder soberano a quien denomina y reconoce como autoridad. La idea filosófica de Rousseau tomó forma política 27 años después en $L a$ Declaración de los derechos del hombre y del ciudadano (aprobada por la Asamblea Nacional Francesa el 26 de agosto de 1789) y adquirió poder legal cuatro años después en la Constitución francesa de 1793.

Mucha agua ha pasado por debajo del puente desde entonces, no obstante, a partir del 16 de diciembre de 1966, prácticamente todos los países del orbe han adoptado el Pacto Internacional de Derechos Civiles y Políticos que, en la sección a) del Artículo 25, otorga a todos los ciudadanos el derecho y la oportunidad de: "Participar en la dirección de los asuntos públicos, directamente o por medio de representantes libremente elegidos" (la modalidad de cursivas no se encuentra en el texto original). Derecho que es equivalente a depositar la soberanía en los representantes políticos o a ejercerla por sí mismos, pero nunca a extinguirla. Ahora bien, si el depósito de la soberanía en los representantes u órganos de gobierno se concibe como una "delegación vinculante", entonces los representantes deciden y actúan por los representados. Pero si el depósito de la soberanía se concibe como una declinación, entonces se tiene la "representatividad fiduciaria" (Rehfeld 2009) o un representante fiduciario (Bobbio 1999). En ese caso la soberanía corre el riesgo de extinguirse porque con la representatividad fiduciaria el gobernante actúa en nombre de los representados y a cuenta de ellos, pero no por ellos. Al no actuar representativamente por los representados, los representantes no 
están obligados a satisfacer la voluntad del electorado (responsiveness). En la representación fiduciaria, cumplir con la transparencia y la rendición de cuentas (accountability) es un mero trámite administrativo, tan apreciado por las democracias representativas, pero con poco sentido si el destino final del erario público se aplicó en acciones extrañas al deseo de los electores contribuyentes.

Así, la representación de la soberanía política se halla en un dilema: declinarla en la representación fiduciaria o sólo delegarla. Con la sola delegación, los representantes están obligados a actuar en el sentido político y moral que los representados indican para dirigir los asuntos públicos. Reciben la confianza de ostentar la capacidad técnica y la congruencia jurídica de las decisiones públicas que adoptaran. Actúan en estricto apego dentro de los límites que los representados les han instruido. De modo que los representantes son responsables de cumplir las instrucciones y los representados serán los responsables solidarios de las consecuencias indicadas. Mientras que en la representación fiduciaria los representantes actúan sin vinculación a la voluntad de sus representados y, por lo tanto, en el decir de Pitkin: "el resultado predominante ha sido que la representación [de tipo fiduciario] ha suplantado a la democracia en lugar de servirla" (2004: 340). Es decir, la declinación de la soberanía en representantes fiduciarios extingue a la propia soberanía al suplantarla. De ahí la necesidad de la Democracia Líquida.

La Democracia Líquida es el modelo de organización política por el cual los ciudadanos no declinan su soberanía en representantes políticos durante períodos fijos, sino que la ejercen o delegan de varias formas. El caso de la delegación soberana no corresponde a una representación política fiduciaria, es decir, se elige a representantes con condiciones vinculantes, imperativas y solidarias con las preferencias de los representados. De modo de los representantes en las cámaras no podrían conducirse por sí mismos o abstenerse a menos que sus electores así lo indiquen.

El modelo líquido está basado en la potestad de sustituir la representación política por la delegación, es decir, un ciudadano tiene la alternativa de participar directamente o depositar en otro su soberanía para que su depositario (denominado representante o apoderado proxy) actúe en el sentido o la intención que le es encomendada de manera imperativa. O si fuera el caso, para que el proxy lo haga de conformidad a su parecer, -si se encuentra autorizado para ello-, en el entendido que la delegación de la soberanía puede serle revocada en cualquier momento para que regrese al ciudadano originario. El apoderado proxy también puede delegarse en otro proxy si lo considera más adecuado o competente y está autorizado para ello por el ciudadano originario.

La soberanía, en el modelo líquido, se ejerce no sólo para elegir a un apoderado proxy ad hoc al caso requerido en la agenda política, sino también para deliberar sobre los asuntos públicos y los mejores apoderados, para 
participar en la elaboración de las políticas públicas, decidir y ejecutar planes y programas de acción. Todo lo anterior puede hacerse opcionalmente, así mismo también existe la alternativa de hacerlo de manera secreta o pública (a menos que la legislación territorial obligue a la secrecía del voto o delegación).

En concreto, la Democracia Líquida puede realizarse en una o varias combinaciones delas siguientes alternativas:(1)el ciudadano puederepresentarse a sí mismo, por medio de la presencia electrónica, en las cámaras o parlamentos; sobre todo en los procesos definitorios y decisorios de las políticas públicas a través del voto electrónico, (2) el ciudadano puede representarse a sí mismo participando electrónicamente con la contabilización de su parte proporcional de soberanía (o sumando las partes proporcionales de quiénes lo hayan elegido como apoderado proxy) en el escaño correspondiente a la representación o representante de su distrito electoral o político o, en su defecto, en el espacio correspondiente al partido político electo de su circunscripción. El partido debería adoptar la modalidad líquida, es decir, cuyos miembros partidistas aceptan que su presencia en la cámara o parlamentos será desplazada por la presencia electrónica de los electores o que su presencia obedece a la función vinculante e imperativa entre los electores y las resoluciones parlamentarias que adoptaran y (3) hacerse representar a través de proxies ad hoc en todo tipo de asambleas según el asunto y diseño de la agenda política.

La primera y la tercera alternativa de la Democracia Líquida, aunque con ausencia de los medios y tecnologías electrónicas, formalmente nacieron en la Constitución francesa de 1793, en cuyo artículo 29 se estableció que "cada ciudadano tiene el mismo derecho para concurrir a la formación de la ley y al nombramiento de su mandatarios o agentes". Esta formulación difiere sutil, pero poderosamente, de la Declaración de 1789. Según la Declaración de 1789 se puede acudir a la formación de ley o dejarla en manos de los representantes, mientras que la Constitución francesa de 1793 permite formar la ley y nombrar a los agentes mandatarios, es decir, a apoderados proxies ad hoc. No es lo mismo un representante (sobre todo si es fiduciario) que un mandatario o agente como apoderado revocable y vinculado. En el modelo líquido, además, no se está forzado a sostener por un período fijo a los apoderados proxies. El proyecto español Democracia 4.0 (Jurado, 2013), todavía por consolidar en la práctica, ilustra esta primera alternativa viabilizada por las tecnologías de comunicación electrónicas.

La segunda alternativa de la Democracia Líquida se encuentra ejemplificada por los partidos líquidos. Destaca el Partido Pirata Internacional. Este partido, fundado en 2006 en Suecia y Alemania, en el año 2009 alcanzó dos escaños en el Parlamento de la Unión Europea; en 2012, dos senadurías nacionales en la República Checa e Islandia; en 2014 alcanzó en Alemania 251 escaños locales y uno en el Parlamento de la Unión Europea; en octubre de 2016 se convirtió 
en la tercera fuerza política de Islandia. Cada legislación territorial puede condicionarlo para sustituir de modo anónimo, o público, la delegación recibida de sus respectivos electores en la representación de los miembros o espacios partidarios en las cámaras. En términos coloquiales, los partidos líquidos son piratas porque no reconocen el "derecho reservado" (como derecho de marca) para hacer política que los representantes fiduciarios aprovechan sólo para sí o que los representantes de partidos ejercen bajo el corporativismo partidista con indiferencia de su electorado. En España pueden enumerarse los proyectos no consolidados del Partido X y del Partido de Internet, así como el intento de organización interna y responsabilidad militante que declaran los partidos Podemos y Barcelona en Comú (BComú). En Italia puede ejemplificarse con el Movimiento 5 Estrellas y en la Argentina con la propuesta del Partido Red. En todos los casos, las tecnologías de información y comunicación funcionan para establecer las vías deliberativas de participación al superar las limitaciones de espacio y tiempo.

Respecto a la tercera alternativa, Ford $(2002,2014)$ y Swierczek (2011) consideran que la Democracia Líquida nació teóricamente en 1884 por la propuesta de Charles Dodgson (mejor conocido como el literato Lewis Carroll) en el texto Los principios de la representación parlamentaria. Dodgson explica la votación proxy como una delegación del voto que puede ser transitiva, es decir, temporal y transferible. La propuesta nació de las inquietudes para obtener un método capaz de seleccionar a los mejores candidatos, conseguir la representación más justa y también la defensa de las preferencias minoritarias. Otros autores (Paulin, 2014) consideran que la Democracia Líquida, bajo denominaciones como democracia deliberativa o votación por proxy, nació en 1912 cuando William S. O’Ren demandó una representación interactiva al exigir ponderar la cantidad de votos a cada representante proxy. El método de ponderación fue diseñado por Gordon Tullock en 1967, quien además propuso la participación directa mientras los debates parlamentarios deberían transmitirse por televisión. De esa forma los electores podían inclinarse por el representante más afín a sus preferencias. Hoy en día eso se puede hacer inmediatamente a través de las plataformas electrónicas, (como lo hizo el 12 de septiembre de 2013, el diputado español Baldoví al disponer de su curul en el sentido de la votación abierta que en Internet tuvieron sus electores). En 1969 James C. Miller, siguiendo a Tullock, argumentó sobre el derecho a votar cualquier cuestión en representación de sí mismo o a través de un representante ajeno al parlamento. Así, los representantes proxies son los apoderados, ajenos a los parlamentos o cámaras, sin filiación a partidos, en quiénes se delega, -no se declina-, la soberanía de cada elector para empoderarlos suficientemente con objeto de definir las políticas públicas. 
De esta tercera alternativa también puede citarse la actual Constitución Ciudadana de Islandia que fue elaborada en una plataforma electrónica de participación y cooperación. En dicha plataforma participó una muestra obtenida por sorteo de ciudadanos voluntarios. La participación fue voluntaria, aunque la colaboración final estuvo condicionada al resultado del sorteo. La construcción de la Constitución de Islandia muestra una mezcla de la primera y tercera modalidades aquí descritas de la Democracia Líquida, pues en parte algunos ciudadanos se representaron a sí mismos al proponerse como voluntarios, otros resultaron representantes de correligionarios, -al menos por sorteo-, y quienes no participaron en el grupo voluntario dejaron a los conciudadanos como proxies de manera tácita. La misma fluidez del modelo líquido obliga a experimentar con casos empíricos que, como todo modelo múltiple, presenta combinatorias que no son universales ni fijas. En consecuencia, todavía algunas de las alternativas están muy alejadas de hallarse jurídicamente reconocidas.

Ahora bien, la Democracia Líquida en sus modalidades (2) y (3) alcanza la participación en las instituciones de representación consiguiendo la deliberación que requiere la cabalidad del modelo directo. La modalidad (1) desplaza a las instituciones representativas en la proporción que los ciudadanos intervengan directamente.

La complejidad de la Democracia Líquida, por su incluyente participación ciudadana, muestra mayor posibilidad de aplicación mientras menor sea la escala demográfica donde se implementa. Por ello, los casos más frecuentes de aplicación del modelo líquido existen a nivel municipal o, incluso, en escalas comunitarias menores, como el caso del presupuesto participativo. El presupuesto participativo puede definirse como el mecanismo reconocido jurídicamente por el cual los ciudadanos ejercen el derecho de voz (para hacer propuestas de inversión pública con montos y programas), de voto (para decidir libre y deliberativamente entre sus planes y programas), de justicia social (para redistribuir proporcionalmente los bienes y servicios a cargo del gobierno) y de monitorización (de los recursos públicos a través de la trasparencia y la rendición de cuentas), para definir las políticas públicas de inversión gubernamental. Ejemplos empíricos que se han convertido en paradigmas de este modelo democrático se encuentran, desde 1989, en los procedimientos del presupuesto participativo en Porto Allegre y Belo Horizonte en Brasil.

Las ventajas que la representación delegada ofrece sobre la representación fiduciaria son precisamente las que provocan la superioridad del modelo democrático participativo en su versión líquida sobre el modelo representativo. Dicha superioridad, en pocas palabras, implica más demos en el kratós, es decir, involucra a más y mejores ciudadanos y lo logra en términos de mayor igualdad soberana. 
Haciendo un parangón de los argumentos de Blum y Zuber (2016) puede afirmarse que la Democracia Líquida involucra más y mejores ciudadanos porque tiene una delegación optativa, flexible y de revocación instantánea que provoca mayor movilización de quienes desean aportar ideas a favor del bien común, ya sea que lo hagan directamente o por medio de los representantes proxy. El representante proxy es un apoderado que actúa en nombre, por y $a$ cuenta, de quien le delegó su poder. De manera que su representación y compromiso son vinculantes, imperativos y corresponsables. No puede convertirse en un representante fiduciario. En consecuencia, el representante proxy apoderado está obligado a ser confiable, puesto que es susceptible de revocación inmediata. También es un agente de los intereses de quienes lo seleccionaron, puesto que es un apoderado solidario.

La Democracia Líquida involucra a los participantes con mayor igualdad soberana que el modelo representativo porque pone al alcance de los electores una mayor igualdad de recursos políticos (a través de la delegación de quienes tienen conocimiento, oportunidad y deseos de participar) con respecto a las formas de hacer valer sus intereses. La igualdad de recursos políticos eleva la igualdad participativa y en consecuencia alcanza mayor calidad y legitimidad de los procedimientos decisionales en las políticas públicas. La potestad de participar directamente o a través de expertos apoderados proxies implica el equilibrio y estandarización de los recursos políticos de los electores. Los electores, -si bien son iguales ante la ley-, no son idénticos, pero tienen los mismos derechos para defender sus intereses y aportar sus perspectivas sobre el bien común a través de sí mismos o sus apoderados. No ocurre así en el modelo representativo porque con la representación política fiduciaria, -aunque los representantes cuenten con la opinión pública y la información técnica de expertos consultores-, la consulta popular no es vinculante y la participación de los expertos no los eleva más allá de la función de asesores, es decir, siempre serán los representantes fiduciarios quienes tomarán las decisiones definitivas. Ello provoca una distancia insalvable entre representados y representantes y pone en riesgo de extinción a la soberanía.

La evidencia del riesgo de extinción de la soberanía, de desaparición de la participación ciudadana, del exterminio de la democracia auténtica, se patentiza en el fenómeno de la desafección política que no sólo está denunciado por los teóricos de las ciencias políticas y sociales (desde Michels hasta Dahl, pasando por Manin, Sustein y tantos otros, abarcando más de un siglo de denuncias), sino por los resultados recurrentes de encuestas populares y ciudadanas y sobre todo, por el abstencionismo y el ejercicio del voto nulo. Otra evidencia del riesgo de extinción de la soberanía, y en consecuencia de la democracia, son los múltiples programas internacionales auspiciados por organismos privados y públicos (Organización de las Naciones Unidas para la educación, la ciencia 
y la cultura (UNESCO), La red del Plan de Escuelas Asociadas a la UNESCO (RedPEA) y un largo etcétera) creados para rescatar y garantizar la educación ciudadana. Programas educativos que reaccionan al peligro de extinción desde la educación básica porque la soberanía se pierde en las generaciones actuales $y$, por ende, no se transmite o cultiva hacia las generaciones futuras.

La sustentabilidad política (en particular el cultivo y legado intergeneracional de la ciudadanía) es imprescindible para la soberanía. $\mathrm{Y}$ por ello, esta noción merece definirse como el modo de organizarse democráticamente para evitar la desafección política en las generaciones actuales y futuras. Dicha organización, en congruencia, sólo puede ejercerse obedeciendo a un modelo de democracia sustentable; aquel que preserva la participación en los asuntos públicos de manera que satisface las necesidades del presente sin comprometer la soberanía ciudadana de las generaciones futuras. Ese modelo se halla por excelencia en la Democracia Líquida.

La Democracia Líquida es el modelo que tiene como misión garantizar la permanencia de la soberanía a lo largo de los procesos en que se deciden las políticas públicas, a través de una intervención directa o delegada y su correspondiente fiscalización. No sólo una permanencia soberana que evite la extinción de la ciudadanía, sino también que garantice que las políticas públicas responderan a la voluntad de los ciudadanos (responsiveness), en la línea de la justicia global. Cuando los ciudadanos no pueden participar por falta de tiempo, no saben en qué sentido pronunciarse por falta de información o no quieren participar directamente por falta de interés en el asunto particular a decidir, entonces pueden hacerlo por medio de representantes delegados proxies. Los proxies son confiables porque están sometidos a la revocabilidad y porque son agentes del interés del representado ya que se hallan bajo la figura de apoderado solidario, es decir, son co-participes de las consecuencias de sus actos representativos.

La Democracia Líquida garantiza la permanencia de la soberanía durante el proceso deliberativo que define las políticas públicas porque el apoderado proxy es revocable y confiable. Es decir, ha sido seleccionado sin necesidad de pertenecer a un partido político porque su elector confía en sus cocimientos para discernir sobre los asuntos a decidir y también da crédito a su probidad. Al proxy, -elegido ad hoc y fuera de los partidos políticos-, se le solicita actuar sobre los asuntos de su especialidad; puede delegar la representatividad que ha recibido y la suya propia en otro proxy si lo considera más capaz en la toma de decisiones. Están obligados a la confiabilidad porque el modelo líquido les impone la revocabilidad inmediata en cualquier momento del proceso deliberativo. Con ello, la revocabilidad de la representación garantiza la sustentabilidad política de quienes delegan sus elecciones. La soberanía es inextinguible en la medida que puede ejercerse potestativamente a través de representantes revocables o de modo directo. 
La Democracia Líquida también garantiza la permanencia de la soberanía en el ciudadano porque el representante proxy es un apoderado. Es decir, el representante proxy sabe que tendrá la obligación de cumplir con los intereses políticos y la expectativa de la probidad moral de quién lo eligió. No es un simple gestor o ejecutor carente de responsabilidad solidaria. El apoderado proxy ha de responder de su representatividad y sus decisiones asumiendo las consecuencias que éstas puedan acarrear no sólo a quienes lo han elegido, sino también a sí mismo.

La Democracia Líquida es garante de la sustentabilidad eco-política porque, tanto en el caso de la participación directa como a través de los apoderados proxies ad hoc y/o las cadenas delegativas de proxies, la soberanía se ejerce empoderándose como agente de la equidad. La equidad se halla vertebrada entre todos los agentes que desean, aún por interés propio y no por razones colectivas, alcanzar la justicia global. Las iniciativas de las políticas públicas en ecología entonces empezarán desde la soberanía misma del pueblo, y no como en los modelos democráticos de representación fiduciaria que nacen de los gobernantes y en el mejor de los casos las hacen pasar por el pueblo.

La sustentabilidad eco-política exige la justicia global porque con ella se conservan y perpetúan los bienes y servicios eco-sistémicos que ofrece la biosfera para todos los pobladores actuales y futuros del globo. Por justicia global pueden entenderse varias cosas. En la concepción de Sachs y Santarius (2007) la justicia global consiste en el reconocimiento que tienen todos los humanos a los derechos básicos y la distribución justa de los recursos de manera que se garantice la supervivencia por encima del bienestar de los demás.

La Democracia Líquida garantiza la participación de todos los interesados en los organismos representativos. De esa manera disuelve la división de clases sociales en los órganos de gobierno, pues otorga a cada participante la misma oportunidad de hacer política de manera autónoma y soberana. Representa la estructura y la dinámica del eco-desarrollo tal y como la postuló Ignacy Sachs (1974) al describir algunos de sus principios: satisfacer necesidades, incluir la participación de la población implicada y defender la separación de los países centrales y periféricos para garantizar el desarrollo de los últimos.

La escala eco-política es simétrica a la escala del eco-desarrollo, pues ambas involucran la participación ciudadana y desean alcanzar la sustentabilidad. Otra razón por la cual tienen mejor aplicación a niveles municipales o menores es, precisamente, la protección y restitución de la biosfera en los ecosistemas regionales. Tal y como lo reconoce la Agenda 21 local como efecto de la Cumbre de la Tierra de Río desde 1992. El eco-desarrollo se postula para los ecosistemas locales, en empresas de niveles pequeños y con la incorporación de la creatividad comunitaria que recoge la sabiduría de las tradiciones étnicas; la eco-política con el modelo líquido se sustenta en la organización 
del gobierno no jerarquizada y, en consecuencia, el desarrollo desde abajo elevándose de manera compensante y normalizante sobre una misma línea equitativa de horizontalidad participativa. Es decir, se aspira a la sustentabilidad ecológica aplicando una sustentabilidad social con un desarrollo que satisfaga las necesidades de las generaciones presentes, comenzado por aquellas más disminuidas (Roland, 2005: 73).

De hecho, la eficaz protección de la biosfera sólo puede alcanzarse resolviendo el problema de las desigualdades sociales y económicas. Esto implica, más allá de la transferencia de tecnologías limpias y la protección de recursos (tanto ecológicos como económicos, según las externalidades) en comunidades vulnerables, también la noción de comercio justo y la eventual compensación de daños ecológicos. La justicia global debe entenderse, en escala espacial global y en escala temporal supra-histórica, como la distribución proporcional tanto de bienes económicos como ecológicos. Es decir, la justicia global es la versión ampliada de la justicia distributiva a lo largo de las dimensiones del espacio y el tiempo con lo cual abarca tanto a la justicia interespecífica como la intergeneracional, pero iniciando con la generación presente en los espacios locales más vulnerables.

\section{Conclusión}

La eco-política, -concomitante al eco-desarrollo-, luego entonces, exige la Democracia Líquida por un cúmulo de razones concatenadas. Razones de índole ecológica y medioambiental vinculadas a la protección de la biosfera. Razones de desarrollo vinculadas a la sustentabilidad. Y finalmente razones sociales y de orden político de imprescindible valor por su aspiración a una mayor justicia.

Recapitulando cabe recordar que la Democracia Líquida es la organización social y política que posibilita en diversas modalidades la participación ciudadana. Participación incluyente de todas las clases sociales, que permite el equilibrio entre clases gracias a la modalidad delegativa en apoderados proxies sujetos a revocación inmediata. Resulta entonces que la Democracia Líquida es preferentemente adecuada a los propósitos de la Agenda 21 local y también para las otras escalas de mayor extensión con el propósito de deliberar, definir y fiscalizar las políticas públicas y de desarrollo que inciden en la sustentabilidad.

La Democracia Líquida satisface las razones de protección a la biosfera porque toma en cuenta las razones ecológicas: construir la normatividad para regular la velocidad de consumo/recuperación de los recursos naturales y la velocidad de contaminación/absorción en los ecosistemas. También satisface las razones medioambientales y económicas respecto al diseño e 
implementación del uso y transferencia de tecnologías limpias y tecnologías regionales rescatadas desde las tradiciones étnicas.

La Democracia Líquida atiende las razones de la sustentabilidad y del desarrollo desde la perspectiva del eco-desarrollo en la medida que, al atender los posibles requerimientos de las generaciones futuras no pierde de vista los correspondientes de las generaciones presentes, tanto en los aspectos globales como en la especificidad de las diversas clases sociales.

La Democracia Líquida se halla involucrada profundamente con las razones sociales que demandan una justicia global. Si bien es cierto que la justicia global en su más amplia expresión exige la justicia intergeneracional -al tomar en cuenta a las futuras generaciones-, y también la justicia interespecifica -al tomar en cuenta la no extinción de las especies no humanas y la no invasión de sus hábitats por los humanos-, también destaca la distribución y redistribución equitativa de los bienes y servicios ecosistémicos para toda las poblaciones, con el explícito reconocimiento de su derecho universal a los recursos naturales.

La Democracia Líquida busca la implementación de esa justicia global, preferenciando su aplicación en las escalas locales, más allá de la justicia distributiva aplicada por las instancias de gobierno. Para tal propósito involucra desde las esferas regionales a los agentes y beneficiarios de los bienes ecológicos y económicos en el proceso incluyente, igualitario y común de la deliberación, decisión y fiscalización de las políticas públicas de orden ambiental. De esa manera protege a la soberanía ciudadana del peligro de la extinción política; amenazada tanto por la desafección participativa dentro los modelos representativos (Aguirre, 2015b), como por el eco-fascismo. A su vez, evita la opacidad, la falta de transparencia y rendición de cuentas en el manejo de programas de desarrollo sustentable. Como lo prueban las experiencias regionales de los presupuestos participativos -en especial en Latinoamérica-, que constituyen una versión micro-modélica del paradigma líquido.

Finalmente, pero no por ello menos importante, la Democracia Líquida protege la sustentabilidad política y por ende garantiza la sustentabilidad ecológica y medioambiental, ya que es el auténtico modelo para velar por la res publica, dado que no hay res más publica que la misma biosfera. 


\section{Referencias bibliográficas:}

Jorge Aguirre, "La aportación de la hermenéutica a la bioética ambiental ante el dilema: biocentrismo versus antropocentrismo en la era de la globalización", en Acta Bioethica, Vol. 21 No. 2, (2015a).

Jorge Aguirre, "Los límites de la representatividad política y las alternativas de la democracia líquida", Revista Internacional de Pensamiento Político, No. 10: 193-216, (2015b).

Disponible en: http://pensamientopolitico.org/Descargas/RIPP10191216.pdf Banco Mundial, ¿Provoca la globalización un agudo proceso de deterioro de las normas ambientales? (Washington D.C., 2000).

Disponible en: http://www.bancomundial.org/temas/globalizacion/cuestiones4.htm

Ulrich Beck, La sociedad del riesgo. Hacia una nueva modernidad (Barcelona, 1998).

Benedicto XVI, Carta Encíclica Caritas in Veritate (Roma, 2009).

Christian Blum and Christina Zuber, "Liquid Democracy: Potentials, Problems, and Perspectives", Journal of Political Philosophy, Vol. 24, No.1, 2016.

Norberto Bobbio, "Rappresentanza e interessi" en M. Bovero (editor) Teoria Generale della politica (Torino, 1999).

René Dubos, Only One Earth: The Care and Maintenance of a Small Planet, United Nations Conference on the Human Environment (Stockholm, 1972).

Guillermo Foladori y Naína Pierri, (Coord.) ¿Sustentabilidad? Desacuerdos sobre el desarrollo sustentable, (Ciudad de México, 2005).

Bryan Ford, Delegative Democracy, 2002. Disponible en: [http://www. brynosaurus.com/deleg/deleg.pdf] (Última fecha de consulta: 16/09/2016).

Bryan Ford, Delegative Democracy Revisited, 2014. Disponible en:

[http://bford.github.io/2014/11/16/deleg.html] (Última fecha de consulta: 16/09/2016).

Francisco, Carta Encíclica Laudato si'. Sobre el cuidado de la casa común (Roma, 2015).

Eduardo Gudynas, "Desarrollo sostenible y ética: historias olvidadas y tensiones persistentes", Rev.Redbioéica/UNESCO, Vol. 6, No. 1, 2015.

Francisco Jurado, "Democracia 4.0: Desrepresentación en el voto telemático de las leyes". Revista Internacional de Pensamiento Político. Vol. 8, 2013.

Manfred Linz et. al., Vivir (bien) con menos, Sobre suficiencia y sostenibilidad (Barcelona, 2007).

Nicola Matteucci, "Soberanía", en Bobbio Norberto, Nicola Matteucci, et al., Diccionario de Política (México, 1982).

Adrian Monjeau, et. al., “¿Sustentabilidad?”, Revista Redbioética/UNESCO, Año 6, Vol. 1, No. 11, enero-junio 2015. 
Shahid Naeem, "Ecosystem Services: Is a Planet Servicing One Species Likely to Function?" In Linking Ecology and Ethics for a Changing World: Values, Philosophy, and Action, Ecology and Ethics, Rozzi R, Pickett STA, Palmer C, Armesto JJ, Callicott JB, (eds.) (Dordrecht, 2013).

Organización de Naciones Unidas, Pacto Internacional de Derechos Civiles y Políticos (Nueva York, 1966).

Organización de Naciones Unidas, Declaración Universal sobre Bioética y Derechos Humanos (Nueva York, 2005) .

Disponible en: http://portal.unesco.org/es/ev.php-URL_ID=31058\&URL_ DO=DO_TOPIC\&URL_SECTION=201.html

Paulin, A. "Through Liquid Democracy to Sustainable Non-Bureacratic Government", JeDem No. 6, Vol. 2, 2014.

Hanna Pitkin, "Representation and Democracy: Uneasy Alliance”, Scandinavian Political Studies, Vol. 27, No. 3, 2004.

Andrew Rehfeld, "Representation Rethought: On Trustees, Delegates, and Gyroscopes in the Study of Political Representation and Democracy", The American Political Science Review, Vol. 103, No. 2, 2009.

David Robertson, The Penguin Dictionary of Politics (Londres, 1993).

Roland Robertson, "Glocalización: tiempo-espacio y homogeneidadheterogeneidad", Cansancio del Leviatán: problemas políticos de la mundialización, (Madrid, 2003).

Fermín Roland, "Deconstruyendo el "desarrollo sustentable" y la alternativa de "decrecimiento" en la era de la globalización", Revista Redbioétical UNESCO, Año 6, Vol. 1, No.11, enero-junio 2015.

Luis Esteban Rubio, "Sobre el ecologismo libertario" en EcoPolítica, (mayo 9, 2016) Disponible en: https://ecopolitica.org/tag/ecologismo-libertario/ Ricardo Rozzi, et. al., (2008). "Filosofía ambiental de campo y conservación biocultural: el programa educativo del Parque Etnobotánico Omora”, Environmental Ethics, No. 30, 2008.

Ignacy Sachs, "Ambiente y estilos de desarrollo", Comercio Exterior, Vol. 24, No. 4, 1974.

Wolfgang Sachs y Tilman Santarius (dirs.) Un futuro justo. Recursos limitados y justicia global (Barcelona, 2007)

Mark Sagoff, "Carrying capacity and ecological economics", BioScience, Vol. 45, No. 9, 1995.

Joaquim Sempere, Mejor con menos. Necesidades, explosión consumista y crisis ecológica (Barcelona, 2009).

John Stuart Mill, Principios de Economía Política (México, 1978).

United Nations Documents, Report of the World Commission on Environment and Development: Our Common Future, 1987. Disponible en: http://www. un-documents.net/wced-ocf.htm 
United Nations Documents, Plan de Aplicación de Johannesburgo de las Decisiones de la Cumbre Mundial sobre el Desarrollo Sostenible de Río de Janeiro (Agenda 21), (1992). Disponible en: http://www.un.org/ spanish/esa/sustdev/pdf/WSSD_PlanImpl.pdf. 